\title{
A novel compound heterozygous mutation in $S L C 5 A 2$ contributes to familial renal glucosuria in a Chinese family, and a review of the relevant literature
}

\author{
SHENTANG LI ${ }^{1}$, YEYI YANG ${ }^{2}$, LIHUA HUANG ${ }^{3}$, MIN KONG $^{1}$ and ZUOCHENG YANG $^{1}$ \\ Departments of ${ }^{1}$ Pediatrics and ${ }^{2}$ Medicine; ${ }^{3}$ Central Laboratory, \\ The Third Xiangya Hospital of Central South University, Changsha, Hunan 410013, P.R. China
}

Received July 22, 2018; Accepted February 21, 2019

DOI: $10.3892 / \mathrm{mmr} .2019 .10110$

\begin{abstract}
Familial renal glucosuria (FRG) is a rare condition that involves isolated glucosuria despite normal blood glucose levels. Mutations in the solute carrier family 5 member 2 (SLC5A2) gene, which encodes sodium-glucose cotransporter 2 (SGLT2), have been reported to be responsible for the disease. Genetic testing of the SLC5A2 gene was conducted in a Chinese family with FRG. A number of online tools were used to predict the potential effect of the identified mutations on SGLT2 function. Additionally, the SLC5A2 mutations previously reported in PubMed were summarized. A novel compound heterozygous mutation (c.514T $>$ C, p.W172R; c. $1540 \mathrm{C}>\mathrm{T}$, p.P514S) of the SLC5A2 gene in a Chinese child with FRG was identified. In total, 86 mutations of the SLC5A2 gene have been reported to be associated with FRG. The novel compound heterozygous mutation (c.514T >C, p.W172R; c.1540C >T, p.P514S) of the SLC5A2 gene may be responsible for the onset of FRG. The present study provides a starting point for further investigation of the molecular pathogenesis of the SLC5A2 gene mutation in patients with FRG.
\end{abstract}

\section{Introduction}

Familial renal glucosuria [FRG; Online Mendelian Inheritance in Man (https://www.omim.org) no. 233100] is a hereditary kidney disease characterized by persistent glucosuria due to a reduction in the renal tubular reuptake of glucose, along with normal blood glucose levels and no other impaired tubular functions (1). In general, FRG is a benign condition that does not require any specific therapy. The ability

Correspondence to: Professor Zuocheng Yang, Department of Pediatrics, The Third Xiangya Hospital of Central South University, 138 Tongzipo Road, Changsha, Hunan 410013, P.R. China E-mail: yang_zcr@126.com

Key words: familial renal glucosuria, solute carrier family 5 member 2 gene, sodium-glucose cotransporter 2, compound heterozygous mutation, literature review of the kidney to reabsorb glucose principally involves the lower-affinity high-capacity sodium-glucose cotransporter 2 (SGLT2), which is located in the proximal convoluted tubule segment $\mathrm{S} 1$ and has a $\mathrm{Na}^{+}$-glucose coupling ratio of 1:1 (2). SGLT2 is encoded by the solute carrier family 5 member 2 (SLC5A2) gene and has 672 amino acids. A large number of case reports conducted using patients of different ethnicities have confirmed that SLC5A2 mutations are responsible for the majority of FRG cases (3-22). Variations in the SLC5A2 gene impact the function of SGLT2, leading to isolated glucosuria. However, various different modes of inheritance have been reported for FRG. Notably, research on SGLT2 has been benefitted in recent years by its identification as a therapeutic target in type 2 diabetes mellitus. In the present study, an association between FRG and a novel compound heterozygous mutation of the SLC5A2 gene was identified. Moreover, all the SLC5A2 mutations in patients with FRG that have been reported to date are summarized in the present study. The present study provides additional information on the genetic mechanism of FRG.

\section{Materials and methods}

Subject. The subject of the present study was a Han Chinese girl. The patient was observed to exhibit glucosuria in the absence of hyperglycemia at the age of 1 year and 9 months, following an initial urine test. Routine urinary analysis showed glucose in the range $+(100 \mathrm{mg} / \mathrm{dl})$ to $+++(500 \mathrm{mg} / \mathrm{dl})$, with no other abnormalities. The quantitative test for urine glucose gave a result of $15.77 \mathrm{~g} / 1.73 \mathrm{~m}^{2} / 24 \mathrm{~h}$. The patient was subjected to an oral glucose tolerance test and exhibited a 2-h postprandial sugar level of $5.1 \mathrm{mmol} / \mathrm{l}$. The patient had no polyuria, polydipsia or polyphagia, and her body weight gain was the same as that of age-matched children. The patient experienced no problems with activity, eating, sleeping or excretory function. There was no reported history of trauma or poisoning. The parents and other family members had no history of glucosuria.

Genetic testing. Following collection of $2 \mathrm{ml}$ blood samples from the parents of the patient, who had no history of FRG, and healthy controls from July to August 2017, genomic DNA 

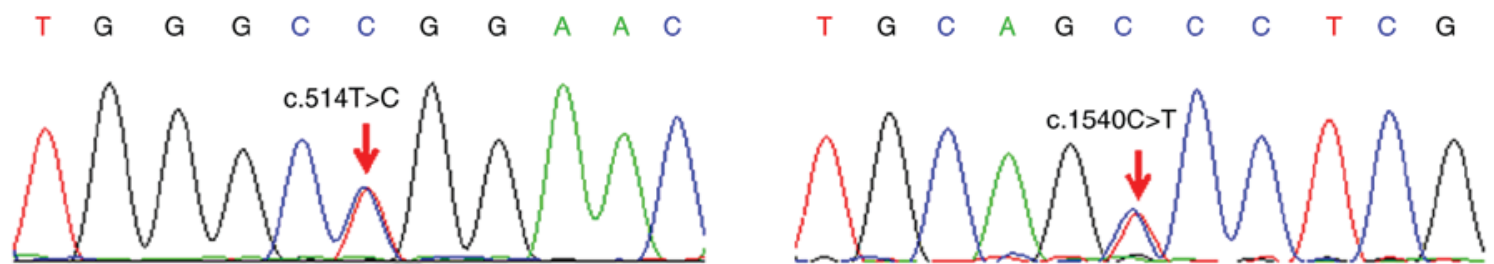

B
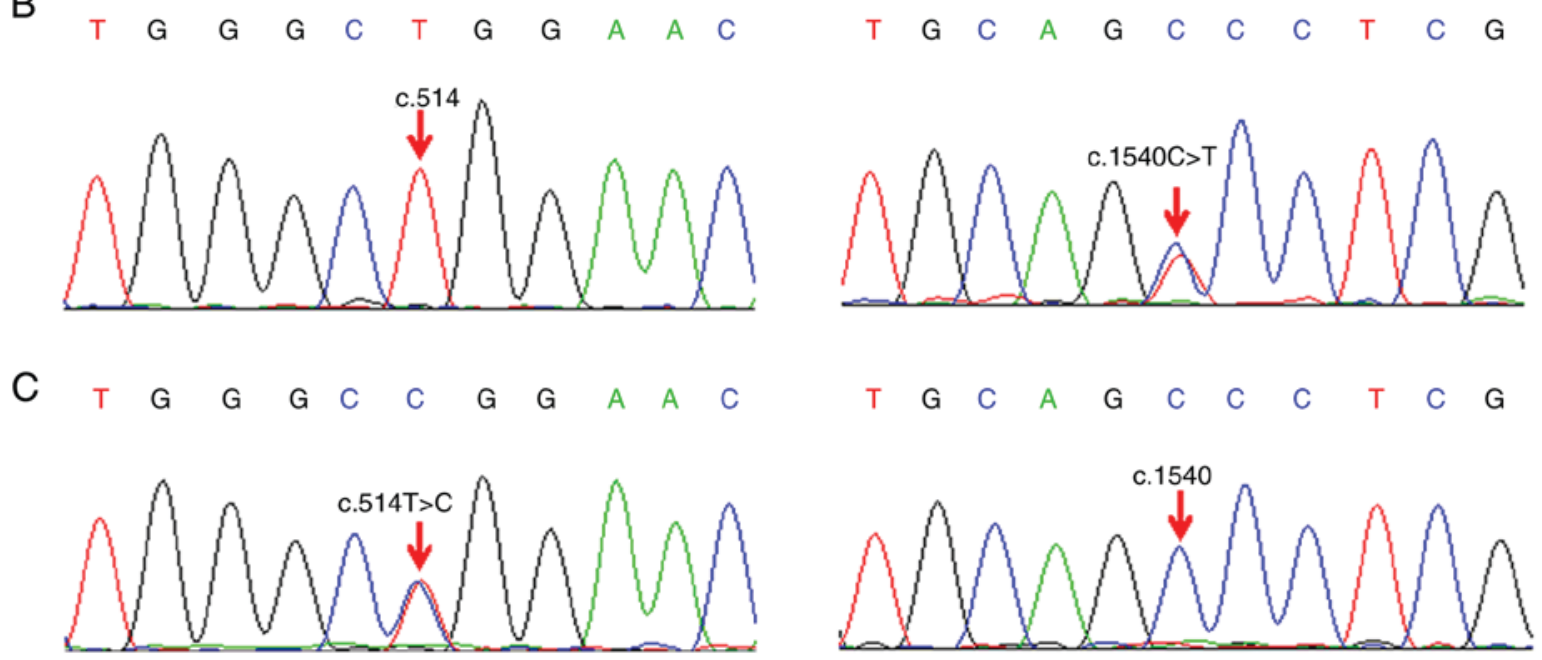

Figure 1. Mutation analysis of the solute carrier family 5 member 2 gene in family members affected with familial renal glucosuria. The positions of the mutations are indicated by the red arrows. (A) The proband harbored a compound heterozygous mutation, c.514T $>C$ and c.1540C $>$ T. (B) The father of the proband was an asymptomatic heterozygous mutation c.1540C $>$ T carrier. (C) The mother of the proband was detected to have an asymptomatic heterozygous mutation c.514T $>$ C.

was extracted from the peripheral blood leukocytes using a Wizard genomic DNA purification kit (Promega Corporation, Madison, WI, USA), according to the manufacturer's protocol. A total of fifty healthy controls (28 males and 22 females; average age $38.84 \pm 29.78$ months) were recruited. Initially, $900 \mu \mathrm{l}$ of cell lysis solution was added to a sterile $1.5 \mathrm{ml}$ microcentrifuge tube with $300 \mu$ collected blood to separate the leukocytes. All the exons and conterminal intronic regions of the $S L C 5 A 2$ gene were amplified via polymerase chain reaction (PCR) using a Thermal Cycler 9700 (Applied Biosystems; Thermo Fisher Scientific, Inc., Waltham, MA, USA). The primers (forward for Exon5, 5'-ACCACTGCGAGG GTTATGAT-3' and reverse for Exon5, 5'-TCCTCACTCAAG CCCAGCAT-3'; forward for Exon12, 5'-GTGTTCATCGTG GTAGTGTCGG-3' and reverse for Exon12, 5'-CCCTCAGTC GAGAAATTCAGG-3') were designed using Primer Premier 5.0 software (Premier Biosoft International, Palo Alto, CA, USA). The PCRs were conducted in a total volume of $20 \mu \mathrm{l}$ containing 1.6 $\mu \mathrm{l}$ DNA, $10 \mu 1$ XX Taq Master Mix (CWBIO, Beijing, China), $0.8 \mu$ l forward primer (Sangon Biotech Co. Ltd., Shanghai, China), $0.8 \mu$ l reverse primer (Sangon Biotech Co., Ltd.) and $\mathrm{dd}_{2} \mathrm{O}$ (added to a final volume of $20 \mu \mathrm{l}$ ), with the following thermal cycling conditions: Denaturing at $94^{\circ} \mathrm{C}$ for $5 \mathrm{~min}, 35$ cycles of denaturing at $94^{\circ} \mathrm{C}$ for $30 \mathrm{sec}$, annealing at $57^{\circ} \mathrm{C}$ for $30 \mathrm{sec}$ and extension at $72^{\circ} \mathrm{C}$ for $30 \mathrm{sec}$, followed by extension at $72^{\circ} \mathrm{C}$ for $10 \mathrm{~min}$. The sequence analysis of the two coding exons of the SLC5A2 gene was performed using an ABI Prism 3130 genetic analyzer (Applied Biosystems; Thermo Fisher Scientific, Inc.). Potential mutations were defined by their exclusion from the Human Gene Mutation
Database (http://www.hgmd.cf.ac.uk) and previously reported mutations on PubMed (http://ncbi.nlm.nih.gov/PubMed/). A total of fifty healthy Chinese individuals containing 100 chromosomes were included as controls. A total of three databases, the dbSNP database of the National Center for Biotechnology Information (http://www.ncbi.nlm.nih.gov/snp/), Exome Variant Server (http://evs.gs.washington.edu/EVS) and 1000 Genomes Project (http://www.1000genomes.org/), were used to eliminate single-nucleotide polymorphisms (SNPs). The study was approved by the Institutional Review Board of the Third Xiangya Hospital, Central South University (Changsha, China).

Homology analysis. A comparative analysis of multiple amino acid sequences of SGLT2 was performed for different species using the Basic Local Alignment Search Tool (https://blast. ncbi.nlm.nih.gov/Blast.cgi). The aligned reference sequences were Homo sapiens (GenBank NP_003032.1), Pan troglodytes (XP_003315117.1), Macaca mulatta (XP_001113206.1), Canis lupus (XP_005621284.1), Bos taurus (NP_976236.1), Mus musculus (NP_573517.1), Rattus norvegicus (NP_072112.2), Danio rerio (NP_998091.1) and Xenopus tropicalis (XP_002940641.2).

Pathogenicity prediction. The functional effects of protein variants were predicted using three online prediction tools, PolyPhen2 (http://genetics.bwh.harvard.edu/pph2/), SIFT (http://sift.jcvi.org) and Mutation Taster (http://www. mutationtaster.org). These online tools predict the pathogenicity of an altered protein based on the number of conserved amino acids and changes in protein structure. 
Table I. Predicted pathogenicity of two missense mutations in the solute carrier family 5 member 2 gene.

\begin{tabular}{lccccc}
\hline Site & Nucleotide changes & Amino acid change & SIFT & PolyPhen-2 & Mutation taster \\
\hline Exon5 & c.514T $>$ C & p.W172R & Deleterious & Probably damaging & Disease causing \\
Exon12 & c.1540C $>$ T & p.P514S & Tolerated & Probably damaging & Disease causing \\
\hline
\end{tabular}

\begin{tabular}{|c|c|c|c|}
\hline & \multicolumn{3}{|c|}{172} \\
\hline sapiens & 150 & YIFTKISVDMFSGAVFIQQALGWNIYASVIALLGITMIYTVTGGLAALMY & 199 \\
\hline troglodytes & 150 & WNIYASVIALLGITMIYTVTGGLAALMY & \\
\hline U.mulatta & 150 & YIFTKISVDMFSGAVFIQQALGWNIYASVIALLGITMIYTVTGGLAALMY & \\
\hline flupus & 150 & YIFTKISVDMFSGAVFIQQALGWNIYASVIALLGITMIYTVTGGLAALMY & \\
\hline B.taurus & 150 & YIFTKISVDMFSGAVFIQQALGWNIYASVIALLGITMIYTVTGGLAALMY & \\
\hline M.musculus & 148 & YIFTKISVDMFSGAVFIQQALGWNIYASVIALLGITMIYTVTGGLAALMY & \\
\hline R.norvegicus & 148 & & \\
\hline rerio & 141 & YíF- & \\
\hline .tropicalis & 1 & YIFTKISVDMFSGAVFIQVALGWNIYLSVIALLVITTIYTVTGGLAALMY & \\
\hline & & & \\
\hline & 00 & VHYLFAIVLFF & \\
\hline tes & 500 & LIPE & \\
\hline M.mulatta & 500 & LIPE & \\
\hline C.lup & 500 & LIPEF & \\
\hline B.taurt & 500 & SCVRPSGCPALLCRVH & \\
\hline M.mu & 498 & LIPEF & \\
\hline egicus & 498 & VHYYLYFAIILFFCSGFLTLAISLCTA & \\
\hline & 491 & GGVHYYFAILLFFCTAILVLFVSYNTP & \\
\hline X.tropicalis & 194 & AVPEFIFGSGSCSAIPSSCPTIICGVHYLYFAIILFLCSGAIVLIVSLCTP & \\
\hline
\end{tabular}

Figure 2. Multiple amino acid sequence alignments of the solute carrier family 5 member 2 gene. The Trp172 and Pro514 residues were highly conserved across various species. The specific position is indicated with a black rectangle.

A This mutation is predicted to be PROBABLY DAMAGING with a score of 0.991 (sensitivity: 0.71 ; specificity: 0.97 )

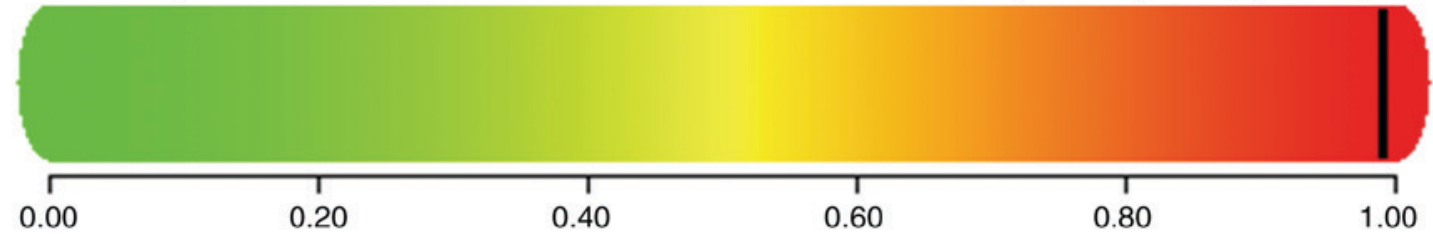

B This mutation is predicted to be PROBABLY DAMAGING with a score of 1.000 (sensitivity: 0.00 ; specificity: 1.00 )

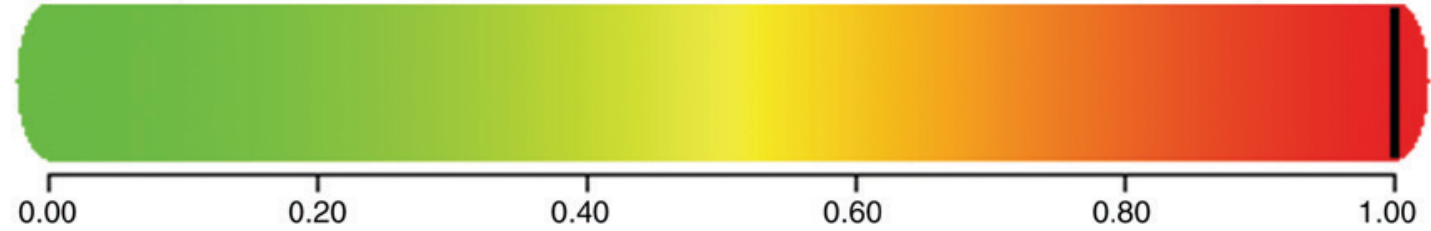

Figure 3. Pathogenicity of identified mutations in the solute carrier family 5 member 2 gene predicted by PolyPhen-2. The two missense mutations (c.514T $>$ C and c. $1540 \mathrm{C}>\mathrm{T}$ ) were both predicted to be 'probably damaging', with a score of (A) 0.991 and (B) 1.000 , respectively.

Literature review. All of the literature previously published on the SLC5A2 mutations (between 2002 and 2017) was retrieved from PubMed. The mutation locations and types for the SLC5A2 gene were summarized.

\section{Results}

Genetic testing of the SLC5A2 gene. According to the direct sequencing of the SLC5A2 gene from the patient with FRG, a novel 1 bp missense mutation in exon 5 (c.514T>C, p.W172R) and a previously reported $1 \mathrm{bp}$ missense mutation in exon 12 (c.1540C >T, p.P514S) were revealed (Fig. 1A). The father of the patient carried the same p.P514S mutation, while her mother had the same p.W172R mutation (Fig. 1B and C). However, neither of the parents exhibited glycosuria or hyperglycemia, with fasting plasma glucose levels of 4.8 and $3.9 \mathrm{mmol} / \mathrm{l}$. Screening of the SLC5A2 gene in healthy Chinese individuals revealed no mutant alleles in exon 5 or exon 12 


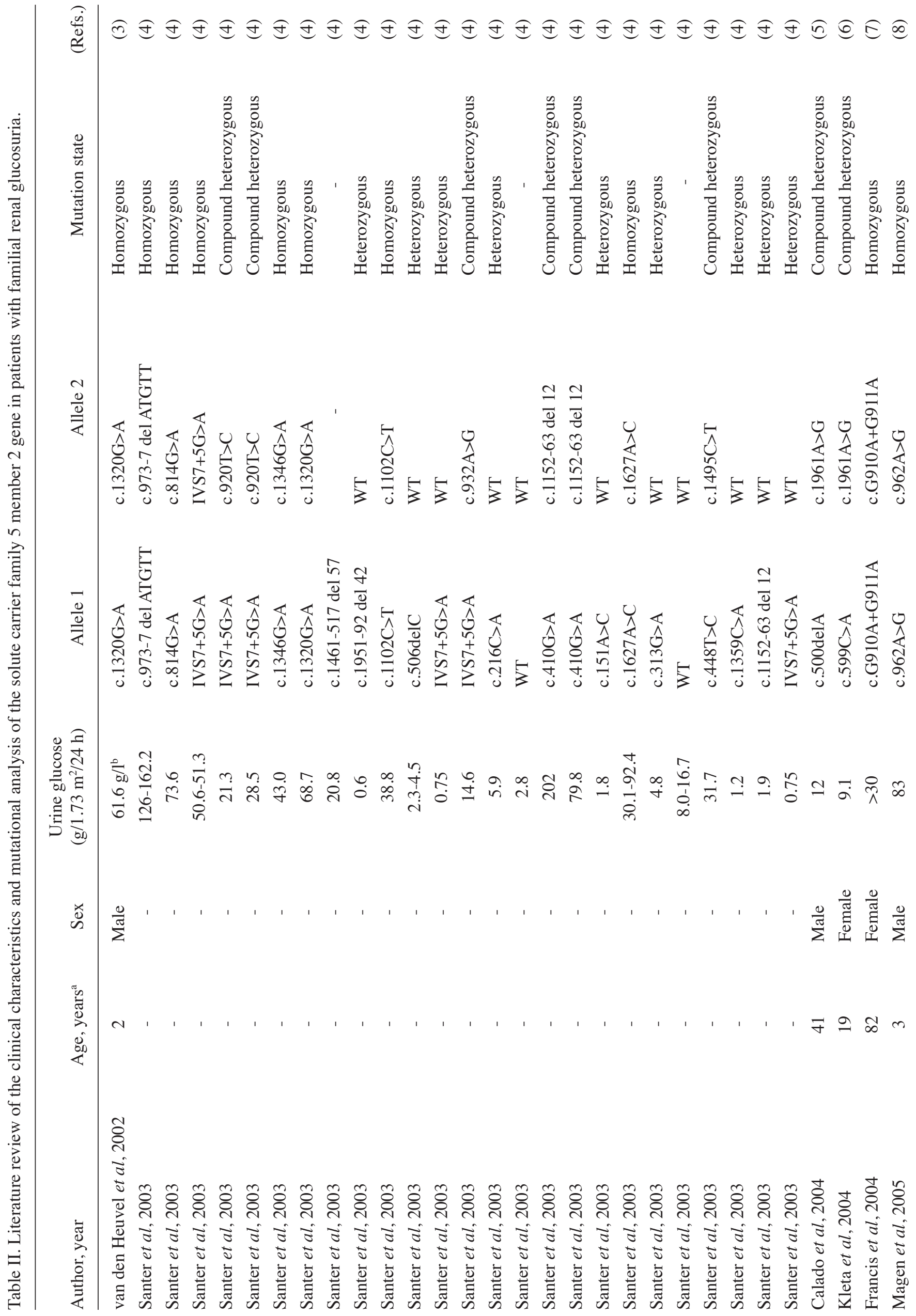




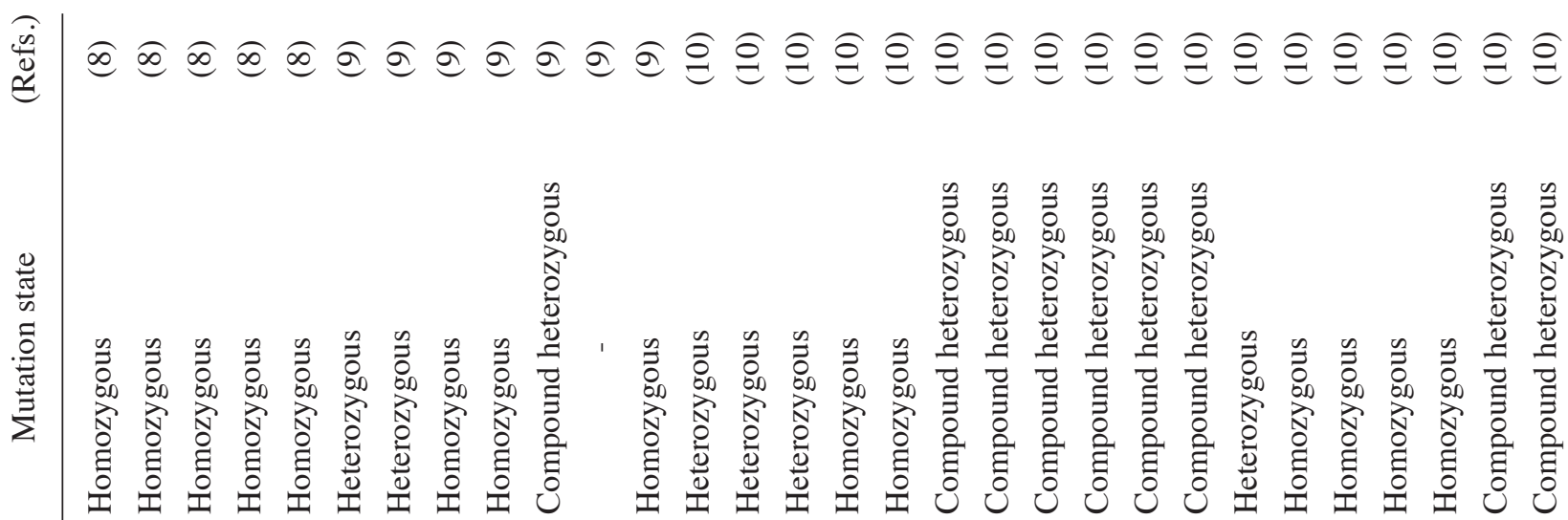

$\frac{\bar{\psi}}{\frac{\pi}{\rho}}$

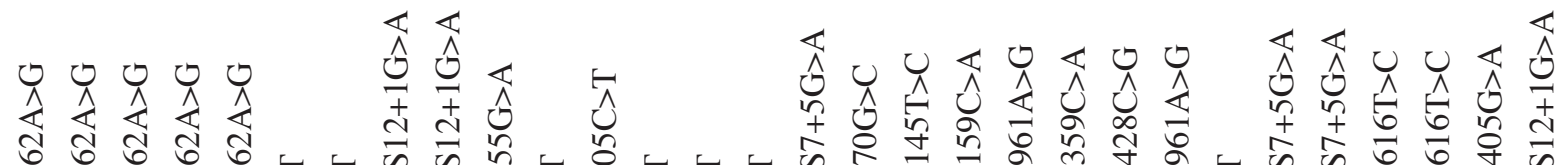

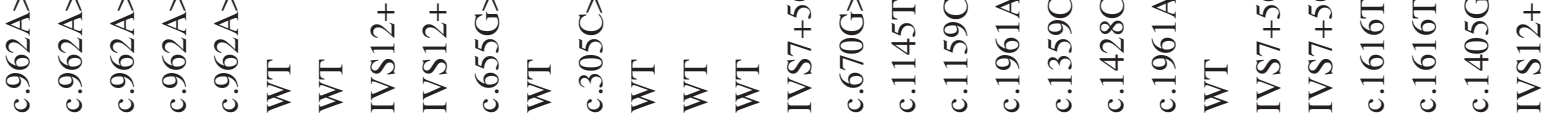

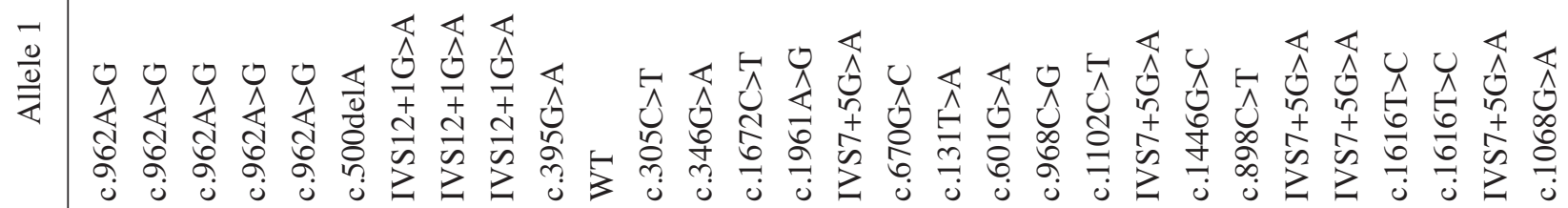

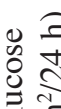

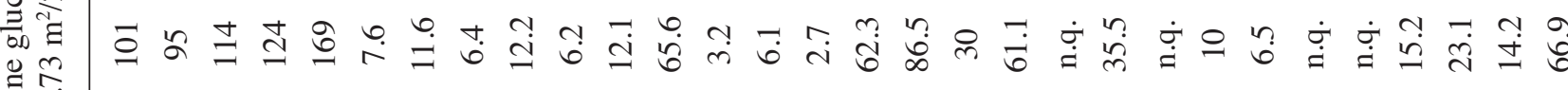

官

席

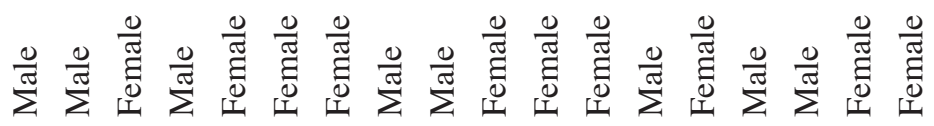

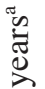
安

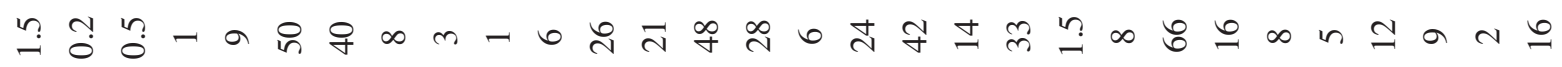

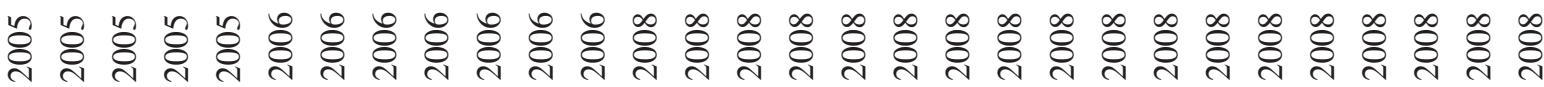

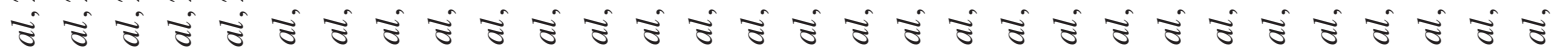

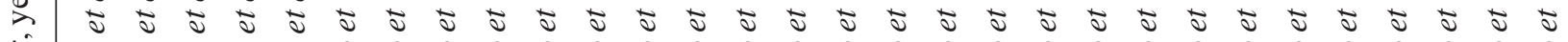

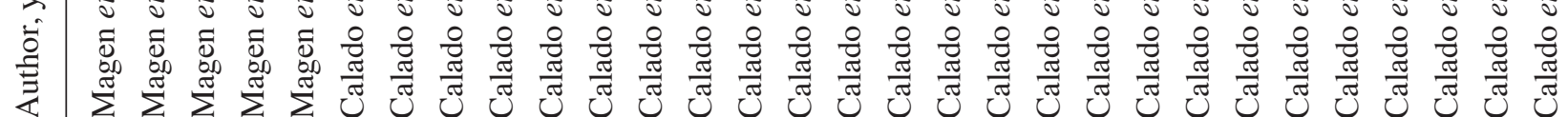




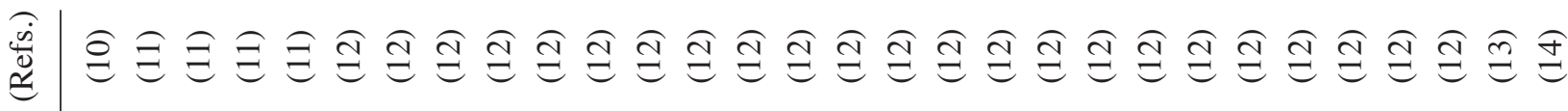

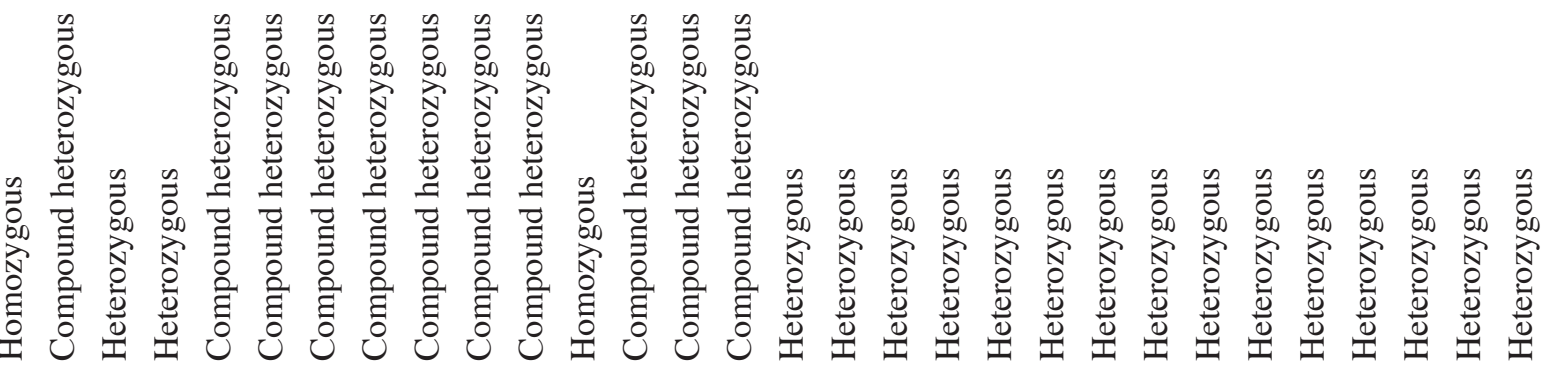

$\stackrel{\stackrel{0}{\varrho}}{=}$

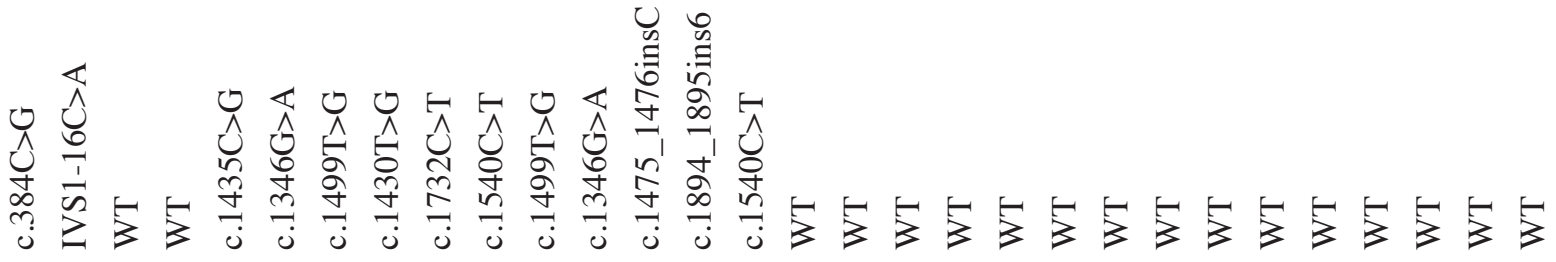

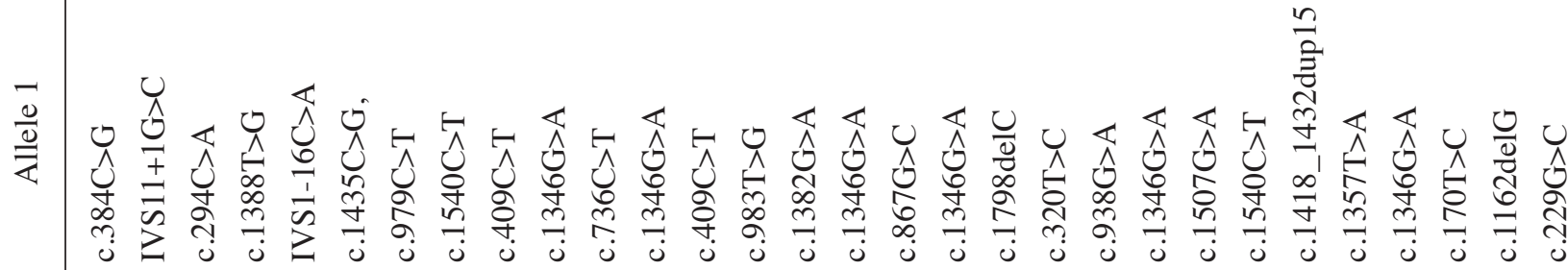
:

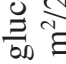
$\stackrel{m}{?}$ i் 实

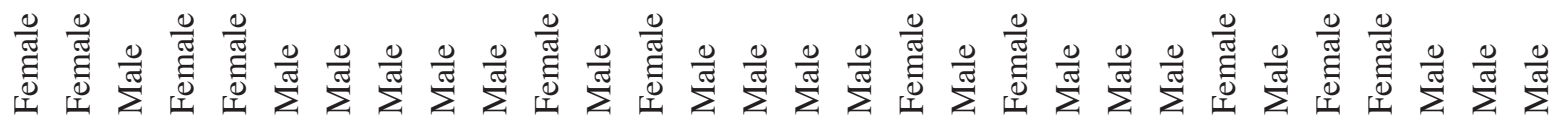
, 


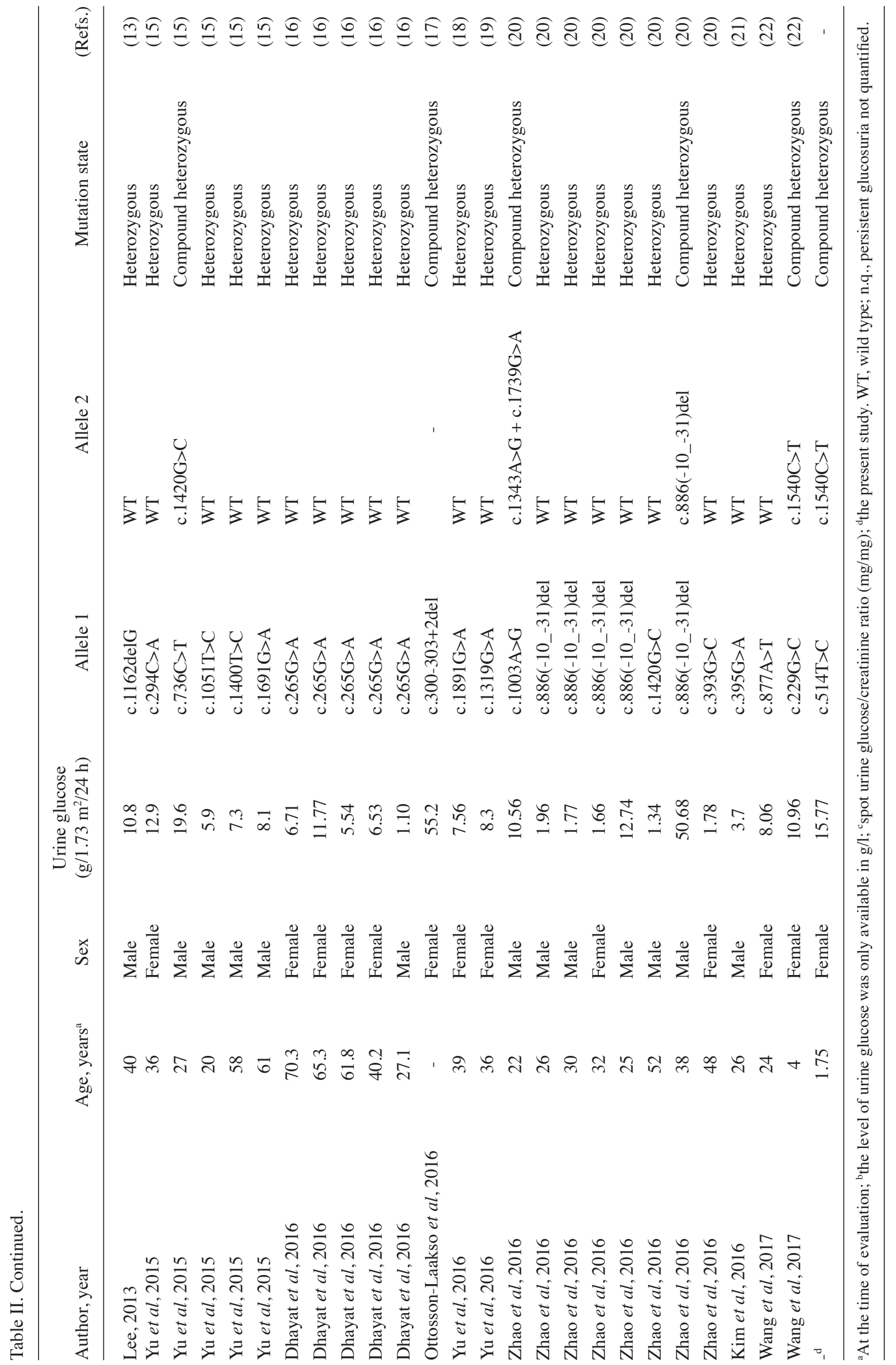


among 100 screened chromosomes. The novel p.W172R mutation was not identified in the three SNP databases used in the present study.

Functional prediction of the SLC5A2 mutations. The results of a comparative analysis of multiple amino acid sequences revealed that the p.W172R and p.P514S variants occurred in highly conserved locations. In addition, the amino acid residues adjacent to the p.W172R and p.P514S variants were also highly conserved among a number of species (Fig. 2). The results of the online analysis performed using PolyPhen-2, SIFT, and Mutation Taster demonstrated that the mutations p.W172R and p.P514S may be deleterious and may be associated with FRG (Fig. 3; Table I).

Results of the literature review. To date, 115 index cases of FRG, including the proband assessed in the present study, have been retrieved in total (Table II). The age of patients upon diagnosis with FRG via an initial urine test is between 2 months and 82 years. Among the 83 cases for which the sex was identified, the male-to-female ratio was 1.18:1. The mutation states are heterozygous, homozygous and compound heterozygous. In summary, 86 mutations of the SLC5A2 gene, including one containing the novel mutation p.W172R in the present study, throughout exons 2-14 and the flanking intronic regions, have been reported to be associated with FRG in patients of different ethnicities (Table III). The three most common mutation sites are located in exon $11(16 / 86=18.60 \%)$, exon 8 $(11 / 86=12.79 \%)$ and exon $4(10 / 86=11.63 \%)$. The mutations are primarily missense $(65 / 86=75.58 \%)$, frameshift $(7 / 86=8.14 \%)$, splicing $(5 / 86=5.81 \%)$, and nonsense $(4 / 86=4.65 \%)$ mutations. Chinese and Korean patients in the East Asian region account for $44.31 \%$ (39/88) of all reported mutations.

\section{Discussion}

FRG is an isolated disorder of glucose transport in the proximal tubule with normal glucose metabolism, and may occur in all age groups. The disease has not been reported to occur at any increased frequency in either males or females. The prevalence of FRG has been suggested to be $0.29 \%$ in the general Caucasian population (23), while it is suspected to have a prevalence of $<0.1 \%$ in Japanese schoolchildren (24). FRG is classified into three types (A, B and O) according to urinary glucose levels (25). Severe FRG (glucosuria $\geq 10 \mathrm{~g} / 1.73 \mathrm{~m}^{2} / 24 \mathrm{~h}$ ), termed type O FRG, is a rare subtype. Patients with type A FRG are characterized by a low renal threshold for glucose and low maximum tubular glucose reabsorption. Those with type $\mathrm{B}$ have a low threshold but normal maximum tubular glucose reabsorption. By contrast, patients with type $\mathrm{O}$ have a complete absence of renal glucose transport (25). In the majority of affected individuals, the condition causes no apparent symptoms or serious effects associated with the excessive urinary excretion of glucose, such as polyuria or enuresis. However, polyuria, enuresis and a mild delay in growth are reported in patients with type O FRG (26). Various other manifestations, such as episodic dehydration and starvation ketosis, and an increased incidence of urinary tract or genital infection, have also been observed in cases of severe FRG (25). Collectively, kidney biopsies in patients with FRG indicate normal kidney tissue via light microscopy, immunofluorescence and electron microscopy (14).

As the member of the sodium glucose cotransporter family, SGLT2 is primarily expressed in the kidney and helps to maintain $\sim 90 \%$ glomerular filtration during glucose reabsorption (27). The SLC5A2 gene is localized in chromosome 16p11.2, with 14 exons, and encodes SGLT2, which contains 672 amino acids. Previous studies have revealed that SLC5A2 mutations are closely associated with the occurrence of FRG (3-22). FRG is primarily caused by mutations in the SLC5A2 gene, which are responsible for the majority of cases. Regarding inheritance patterns, FRG may be inherited in an autosomal recessive or autosomal dominant pattern. However, studies have demonstrated that the inheritance of FRG may best be described as co-dominant with incomplete penetrance $(4,22)$. Previous studies have suggested that patients with heterozygous $S L C 5 A 2$ mutations are likely to exhibit mild glucosuria (glucosuria $<10 \mathrm{~g} / 1.73 \mathrm{~m}^{2} / 24 \mathrm{~h}$ ), while homozygous or compound heterozygous mutations tend to lead to severe glucosuria $(4,8,12)$. Not all individuals with heterozygous $S L C 5 A 2$ variants exhibit glucosuria; this highlights the issue of penetrance (28). Penetrance is difficult to determine reliably, even for genetic diseases that are caused by a single polymorphic allele. For many hereditary diseases, the onset of symptoms is age-associated and affected by environmental factors, such as diet and climate, in addition to genetic cofactors and the epigenetic regulation of expression (29). Specifically, a diagnosis of FRG depends on the detection of urine glucose levels, thus it may be missed due to alterations in the urine glucose level. For example, the urine glucose level will be impacted by the amount of sugar consumed recently.

In the present study, two missense mutations in the SLC5A2 gene of a Chinese patient with FRG accompanied by benign clinical symptoms were reported, one of which was a novel missense mutation (c.514T $>$ C; p.W172R). A total of two previous studies reported that the p.P514S mutation led to FRG with single heterozygous or compound heterozygous status (p.G77R, p.P514S; p.V477G, p.P514S) $(12,22)$. The parents of the proband in the present study carried missense mutations at different locations in terms of SLC5A2 cDNA position, but neither of them had history of glucosuria. Nevertheless, the patient, with p.W172R and p.P514S missense mutations, exhibited severe glucosuria. It is possible that wild-type SGLT2 may serve a compensatory role during the occurrence of FRG caused by SLC5A2 mutations. These results indicated that the inheritance patterns of FRG are best described as co-dominant. Therefore, it may be surmised that the p.W172R and p.P514S compound heterozygous mutation of the $S L C 5 A 2$ gene contributes to FRG.

SGLT2 has 14 transmembrane helices (TMHs) with the hydrophobic $\mathrm{N}$ - and $\mathrm{C}$-terminal domains lying in the extracellular space and contains a sodium solute symporter domain (http://smart.embl-heidelberg.de/; TMHMM server V.2.0). An earlier study on the transport mechanisms of the SGLT1/SGLT2 chimera indicated that the C-terminal domain determined sugar affinity and selectivity (30). p.W172 and p.P514 are localized in the extracellular loops between TMH 4 and TMH 5, and between TMH 12 and 13, respectively (Fig. 4). p.W172 and p.P514 residues were identified to be highly conserved among numerous other species. Meanwhile, 


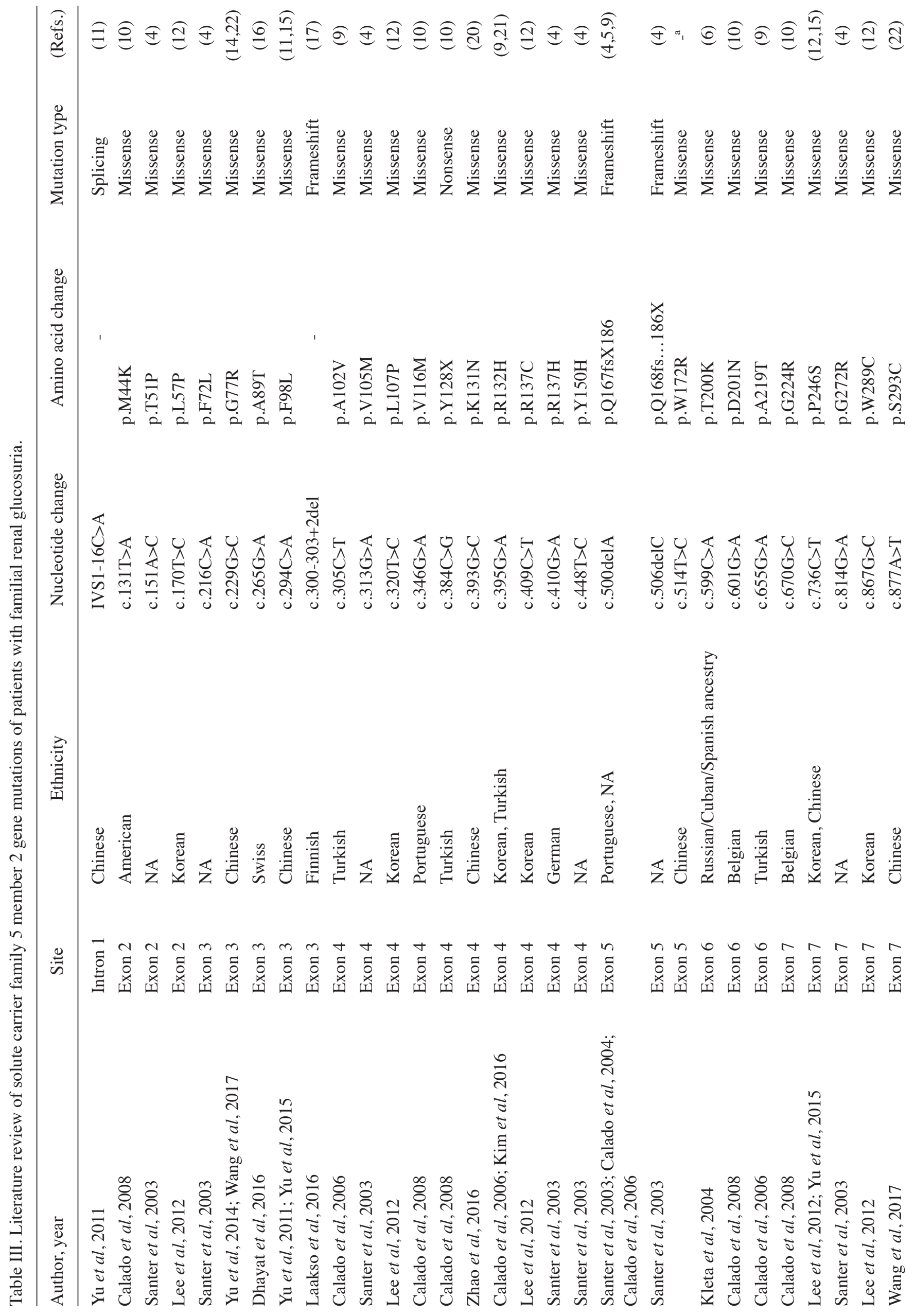




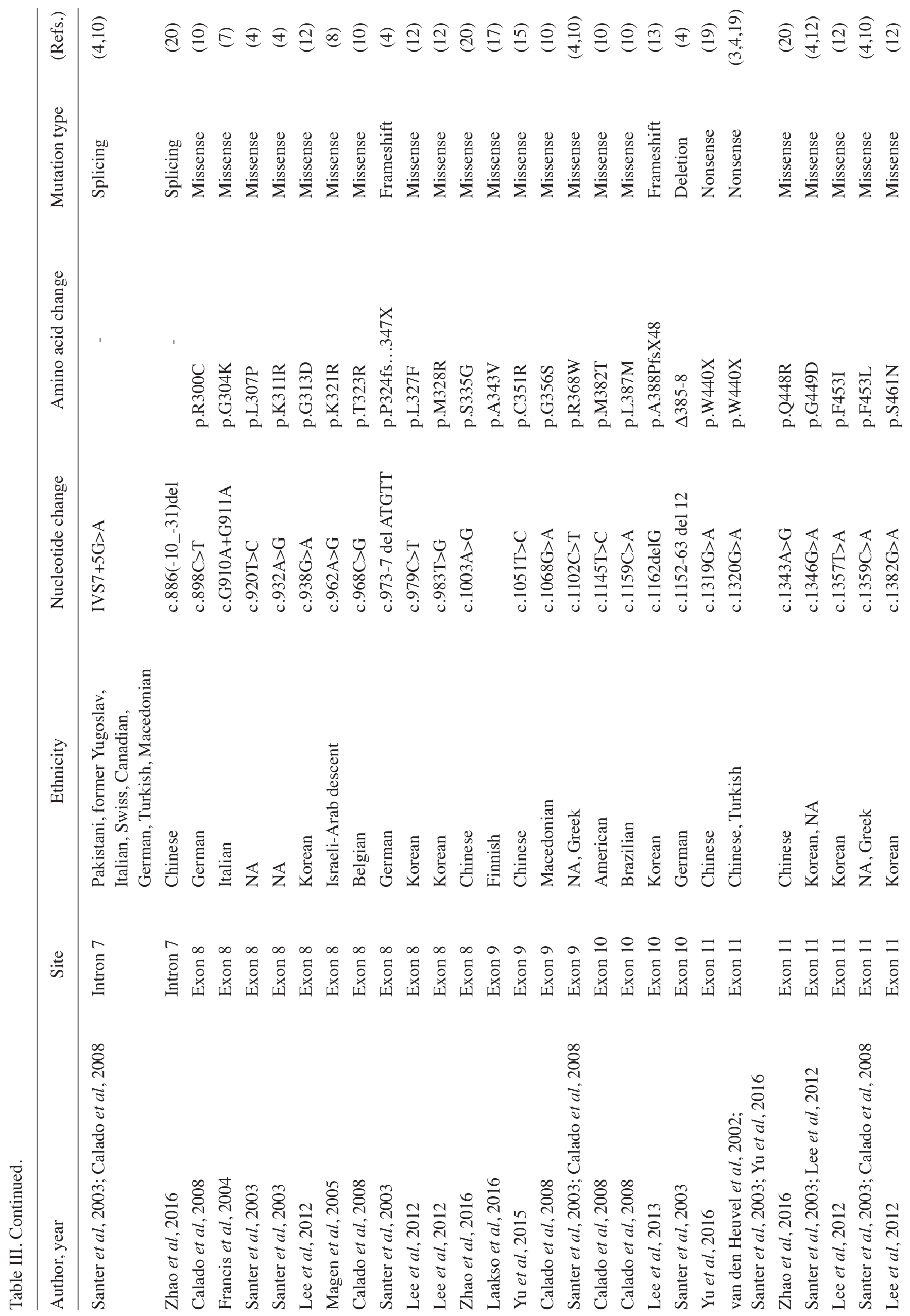




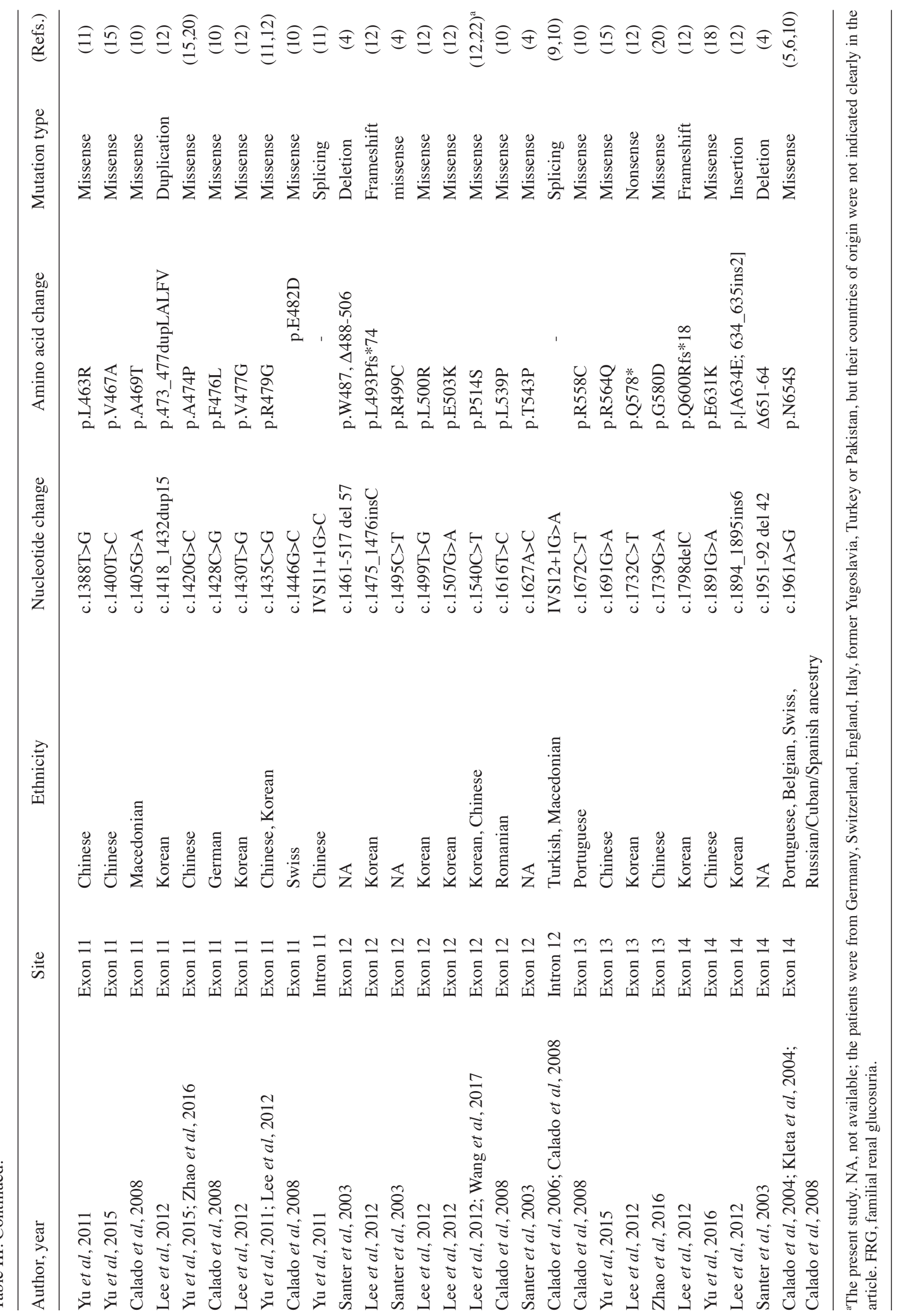




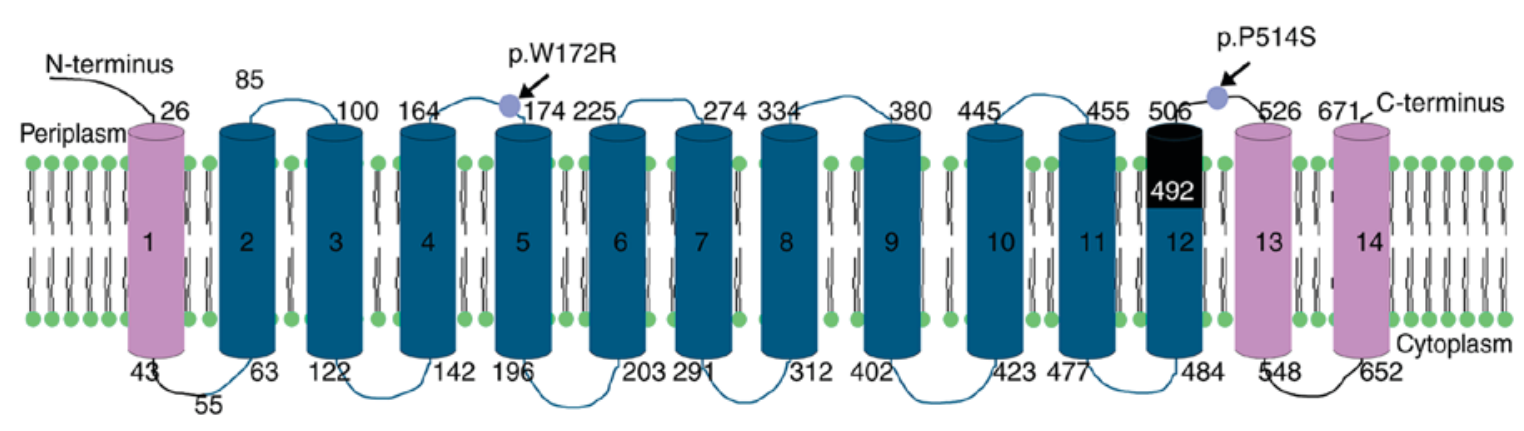

Figure 4. Schematic diagram of SGLT2. The SGLT2 protein is represented as a 14 transmembrane domain protein with extracellular amino and carboxyl termini. Transmembrane helices 1-14 are illustrated as cylinders. Arabic numerals represent the number of amino acid. The blue lines and cylinders indicate the sodium solute symporter domain. The sites of the mutations (p.W172R and p.P514S) identified in the present study are denoted by arrows. SGLT2, sodium-glucose cotransporter 2 .

these two mutations were not detected in 100 chromosomes derived from 50 healthy and unrelated individuals, or in the three SNP databases retrieved for this study, indicating that this is not a common polymorphism. Moreover, the pathogenicity prediction based on three online algorithms demonstrated that the mutations p.W172R and p.P514S may be deleterious. A previous in vitro functional expression study of SLC5A2 mutations demonstrated that six missense mutations (c.294C >A, c.736C >T, c.1051T >C, c.1400T >C, c. $1420 \mathrm{G}>\mathrm{C}$ and c.1691G $>\mathrm{A}$ ) appeared to affect transport activity by reducing intrinsic transporter activity, impairing protein insertion into the cell membrane, suppressing protein synthesis and promoting protein removal or degradation (15). Therefore, it is thought that these two mutation sites may be of particular functional significance in the pathogenesis of FRG. Further in vitro research projects on kidney cells involving the construction of specific plasmids are required to confirm the pathogenic nature of these mutations.

According to a review of the literature, 86 mutations in the SLC5A2 gene have been reported to be associated with FRG. Missense, frameshift and splicing mutations are the most common among these. It is likely that mutations of the SLC5A2 gene may occur among different demographic groups. Among the 115 patients with FRG considered in the present study, there is no specific age at diagnosis that is most common, nor a significant sex difference. A majority of severe FRG cases exhibit mutation states that are homozygous or compound heterozygous, suggesting that the mode of inheritance may be explained as a co-dominant pattern with incomplete penetrance. It is noteworthy that three FRG patients had no mutations in the SLC5A2 gene $(4,9)$. In addition, not all individuals with similar or identical mutations have the same degree of increased glucose excretion, suggesting a role for non-genetic factors or other genes in glucose transport. Also, other SGLTs that are known to be expressed in the kidney and whose functions have not yet been clarified are candidate modified genes in cases of FRG $(4,31)$. In the majority of affected individuals, the condition causes no apparent symptoms or serious effects, such as hypoglycemia, polyuria or dehydration. Therefore, patients with FRG have a good prognosis. Based on this, SGLT2 inhibitors are gradually becoming a promising antihyperglycemic medication with which to improve the prognosis of diabetic kidney disease while maintaining cardiovascular safety, according to a number of clinical trials (32). Thus, understanding the functional significance and pathogenic role of variants in the SLC5A2 gene is essential.

However, there remain certain limitations to the present study. First, histological analysis of the kidneys in the patient was not performed to verify the expression of SGLT2. Second, since there was only one case included in the present study, it was difficult to acquire abundant information regarding the genotype-phenotype association. Third, further in vitro studies are required to confirm the pathogenic variants.

In conclusion, the present study identified a compound heterozygous mutation (p.W172R and p.P514S) of the SLC5A2 gene in a Chinese patient with FRG. The mechanism whereby the p.W172R and p.P514S mutations impair SGLT2 function, in addition to the exact mechanism of abnormal glucose transport in FRG, requires further investigation.

\section{Acknowledgements}

Not applicable.

\section{Funding}

This study was funded by the New Xiangya Talent Project of the Third Xiangya Hospital of the Central South University (grant no. JY20150312).

\section{Availability of data and materials}

The datasets used and/or analyzed during the current study are available from the corresponding author on reasonable request.

\section{Authors' contributions}

SL and ZY conceived and designed the experiments. SL conducted the experiments. YY, LH and MK were involved in conducting the experiments. SL collected the data and wrote the paper. ZY revised the manuscript. All authors read and approved the final paper.

\section{Ethics approval and consent to participate}

The study was approved by the Institutional Review Board of the Third Xiangya Hospital, Central South University 
(Changsha, China), and written informed consent was obtained from all participants.

\section{Patient consent for publication}

Not applicable.

\section{Competing interests}

The authors declare that they have no competing interests.

\section{References}

1. Wright EM, Hirayama BA and Loo DF: Active sugar transport in health and disease. J Intern Med 261: 32-43, 2007.

2. Kanai Y, Lee WS, You G, Brown D and Hediger MA: The human kidney low affinity Na+/glucose cotransporter SGLT2 Delineation of the major renal reabsorptive mechanism for D-glucose. J Clin Invest 93: 397-404, 1994.

3. van den Heuvel LP, Assink K, Willemsen M and Monnens L: Autosomal recessive renal glucosuria attributable to a mutation in the sodium glucose cotransporter (SGLT2). Hum Genet 111: 544-547, 2002

4. Santer R, Kinner M, Lassen CL, Schneppenheim R, Eggert P, Bald M, Brodehl J, Daschner M, Ehrich JH, Kemper M, et al: Molecular analysis of the SGLT2 gene in patients with renal glucosuria. J Am Soc Nephrol 14: 2873-2882, 2003.

5. Calado J, Soto K, Clemente C, Correia P and Rueff J: Novel compound heterozygous mutations in SLC5A2 are responsible for autosomal recessive renal glucosuria. Hum Genet 114: 314-316, 2004

6. Kleta R, Stuart C, Gill FA and Gahl WA: Renal glucosuria due to SGLT2 mutations. Mol Genet Metab 82: 56-58, 2004.

7. Francis J, Zhang J, Farhi A, Carey H and Geller DS: A novel SGLT2 mutation in a patient with autosomal recessive renal glucosuria. Nephrol Dial Transplant 19: 2893-2895, 2004.

8. Magen D, Sprecher E, Zelikovic I and Skorecki K: A novel missense mutation in SLC5A2 encoding SGLT2 underlies autosomal-recessive renal glucosuria and aminoaciduria. Kidney Int 67: 34-41, 2005.

9. Calado J, Loeffler J, Sakallioglu O, Gok F, Lhotta K, Barata J and Rueff J: Familial renal glucosuria: SLC5A2 mutation analysis and evidence of salt-wasting. Kidney Int 69: 852-855, 2006.

10. Calado J, Sznajer Y, Metzger D, Rita A, Hogan MC, Kattamis A, Scharf M, Tasic V, Greil J, Brinkert F, et al: Twenty-one additional cases of familial renal glucosuria: Absence of genetic heterogeneity, high prevalence of private mutations and further evidence of volume depletion. Nephrol Dial Transplant 23: 3874-3879, 2008.

11. Yu L, Lv JC, Zhou XJ, Zhu L, Hou P and Zhang H: Abnormal expression and dysfunction of novel SGLT2 mutations identified in familial renal glucosuria patients. Hum Genet 129: 335-344, 2011.

12. Lee H, Han KH, Park HW, Shin JI, Kim CJ, Namgung MK, Kim KH, Koo JW, Chung WY, Lee DY, et al: Familial renal glucosuria: A clinicogenetic study of 23 additional cases. Pediatr Nephrol 27: 1091-1095, 2012.

13. Lee YW: Clinical and genetic analysis in a patient with primary renal glucosuria: Identification of a novel mutation in the $S L C 5 A 2$ gene. Exp Ther Med 6: 1532-1534, 2013.

14. Yu L, Hou P, Lv JC, Liu GP and Zhang H: A novel sodium-glucose co-transporter 2 gene (SGLT2) mutation contributes to the abnormal expression of SGLT2 in renal tissues in familial renal glucosuria. Int Urol Nephrol 46: 2237-2238, 2014.
15. Yu L, Hou P, Lv JC, Liu GP and Zhang H: Novel SLC5A2 variants contribute to renal glucosuria in Chinese families: Abnormal expression and dysfunction of variant SLC5A2. Hum Mutat 36: 79-86, 2015.

16. Dhayat N, Simonin A, Anderegg M, Pathare G, Lüscher BP, Deisl C, Albano G, Mordasini D, Hediger MA, Surbek DV, et al: Mutation in the monocarboxylate transporter 12 gene affects guanidinoacetate excretion but does not cause glucosuria. J Am Soc Nephrol 27: 1426-1436, 2016.

17. Ottosson-Laakso E, Tuomi T, Forsén B, Gullström M, Groop PH, Groop L and Vikman P: Influence of familial renal glycosuria due to mutations in the SLC5A2 gene on changes in glucose tolerance over Time. PLoS One 11: e0146114, 2016.

18. Yu L, Xu Q, Hou P and Zhang H: Decreased expression and function of sodium-glucose co-transporter 2 from a novel C-terminal mutation: A case report. BMC Nephrol 17: 31, 2016.

19. Yu L, Hou P, Liu GP and Zhang H: Novel SLC5A2 mutation contributes to familial renal glucosuria: Abnormal expression in renal tissues. Exp Ther Med 12: 649-652, 2016.

20. Zhao X, Cui L, Lang Y, Liu T, Lu J, Wang C, Tuffery-Giraud S, Bottillo I, Wang X and Shao L: A recurrent deletion in the SLC5A2 gene including the intron 7 branch site responsible for familial renal glucosuria. Sci Rep 6: 33920, 2016.

21. Kim KM, Kwon SK and Kim HY: A Case of Isolated Glycosuria Mediated by an SLC5A2 gene mutation and characterized by postprandial heavy glycosuria without salt wasting. Electrolyte Blood Press 14: 35-37, 2016.

22. Wang X, Yu M, Wang T, Zhang H, Ping F, Zhang Q, Xu J, Feng K and Xiao X: Genetic analysis and literature review of Chinese patients with familial renal glucosuria: Identification of a novel SLC5A2 mutation. Clin Chim Acta 469: 105-110, 2017.

23. Crombie DL: Incidence of glucosuria and diabetes. Proc R Soc Med 55: 205-207, 1962.

24. Urakami T, Yoda M, Yoshida K, Mine Y, Aoki M and Suzuki J: Renal glucosuria in schoolchildren: Clinical characteristics. Pediatr Int 60: 35-40, 2018.

25. Santer R and Calado J: Familial renal glucosuria and SGLT2: From a mendelian trait to a therapeutic target. Clin J Am Soc Nephrol 5: 133-141, 2010.

26. Scholl-Burgi S, Santer R and Ehrich JH: Long-term outcome of renal glucosuria type $\mathrm{O}$ : The original patient and his natural history. Nephrol Dial Transplant 19: 2394-2396, 2004.

27. Wright EM: Renal Na(+)-glucose cotransporters. Am J Physiol Renal Physiol 280: F10-F18, 2001.

28. De Marchi S, Cecchin E, Basile A, Proto G, Donadon W, Jengo A, Schinella D, Jus A, Villalta D, De Paoli P, et al: Close genetic linkage between HLA and renal glycosuria. Am J Nephrol 4: 280-286, 1984.

29. Hou J, van Leeuwen J, Andrews BJ and Boone C: Genetic network complexity shapes background-dependent phenotypic expression. Trends Genet 34: 578-586, 2018.

30. Panayotova-Heiermann M, Loo DD, Kong CT, Lever JE and Wright EM: Sugar binding to $\mathrm{Na}+$ /glucose cotransporters is determined by the carboxyl-terminal half of the protein. J Biol Chem 271: 10029-10034, 1996.

31. Freitas HS, D'Agord Schaan B, da Silva RS, Okamoto MM, Oliveira-Souza M and Machado UF: Insulin but not phlorizin treatment indu ces a transient increase in GLUT2 gene expression in the kidney of diabetic rats. Nephron Physiol 105: p42-p51, 2007.

32. Alicic RZ, Johnson EJ and Tuttle KR: SGLT2 Inhibition for the prevention and treatment of diabetic kidney disease: A review. Am J Kidney Dis 72: 267-277, 2018.

This work is licensed under a Creative Commons Attribution-NonCommercial-NoDerivatives 4.0 International (CC BY-NC-ND 4.0) License. 